\title{
Regulation of Stem Cells in the Zebra Fish Hematopoietic System
}

\author{
H.-T. HUANG AND L.I. ZoN \\ Harvard Medical School, Stem Cell Program and Division of Hematology/Oncology, \\ Children's Hospital and Dana Farber Cancer Institute, Howard Hughes Medical Institute, \\ Harvard Stem Cell Institute, Boston, Massachusetts 02115
}

\begin{abstract}
Hematopoietic stem cells (HSCs) have been used extensively as a model for stem cell biology. Stem cells share the ability to self-renew and differentiate into multiple cell types, making them ideal candidates for tissue regeneration or replacement therapies. Current applications of stem cell technology are limited by our knowledge of the molecular mechanisms that control their proliferation and differentiation, and various model organisms have been used to fill these gaps. This chapter focuses on the contributions of the zebra fish model to our understanding of stem cell regulation within the hematopoietic system. Studies in zebra fish have been valuable for identifying new genetic and signaling factors that affect HSC formation and development with important implications for humans, and new advances in the zebra fish toolbox will allow other aspects of HSC behavior to be investigated as well, including migration, homing, and engraftment.
\end{abstract}

Stem cells and early progenitors are important for organ formation during development and support tissue function throughout an organism's lifetime. These principles are illustrated in the blood system, where HSCs are needed to maintain a constant pool of progenitors committed to the various blood lineages to replenish the mature blood cells that turn over. Consequently, HSCs, like other stem cells, have the ability to self-renew in order to generate more HSCs and to differentiate along multiple lineage pathways to make erythrocytes, megakaryocytes, monocytes/macrophages, neutrophils, or lymphocytes. Because of their potential therapeutic value, HSCs have been the subject of intense study for many years, but methods for maintaining them in vitro and differentiating them into specific cell types are limited. In addition, HSCs remain difficult to study because their ontogeny is tightly regulated in a spatial and temporal manner, with progenitors of varying potentials arising from different sites.

Research using the zebra fish (Danio rerio) model has provided new insights into some of the major issues regarding the regulation and function of HSCs (Davidson and Zon 2004; Carradice and Lieschke 2008; Orkin and Zon 2008). The advantages of using zebra fish include its high fecundity, rapid growth, and external development of transparent embryos, which facilitates visualization of early embryonic processes. Most importantly, the genes controlling hematopoiesis are highly conserved in fish and mammals. Many blood mutants have been isolated from large-scale genetic screens (Ransom et al. 1996; Weinstein et al. 1996), thereby providing powerful tools for dissecting the molecular aspects of HSC control.

\section{EMBRYONIC HEMATOPOIESIS: PRIMITIVE AND DEFINITIVE WAVES}

The onset of hematopoiesis in the early embryo is characterized by the induction of distinct progenitors at various anatomical sites. Hematopoiesis subsequently shifts location during the course of development, as depicted in Figure 1. Blood formation occurs in two major waves. In zebra fish, the primitive wave consists of the formation of primitive erythrocytes $\left(\right.$ gatal $\left.^{+}\right)$in the intermediate cell

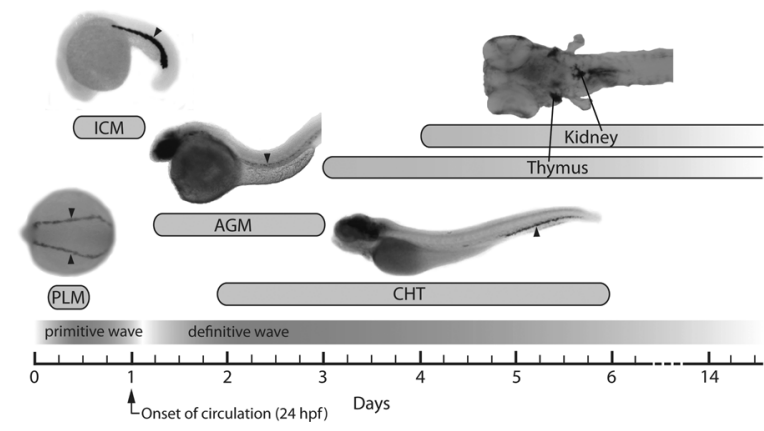

Figure 1. Embryonic hematopoiesis in zebra fish. Hematopoiesis occurs in two waves. In zebra fish, the primitive wave begins with the induction of precursors in the bilateral stripes of the posterior lateral mesoderm (PLM), which converge medially to form the intermediate cell mass (ICM) region where primitive erythrocytes are formed. After the onset of circulation (about 24 hours postfertilization [hpf]), definitive HSCs appear in the aorta-gonad mesonephros (AGM) region. These cells subsequently migrate and colonize the caudal hematopoietic tissue (CHT), thymus, and kidney. Each hematopoietic site is identified by in situ hybridization for gatal at $14 \mathrm{hpf}$ (PLM), gatal at $20 \mathrm{hpf}$ (ICM), c-myb at $36 \mathrm{hpf}$ (AGM), scl at day 4 (CHT), and c-myb at day 6 (thymus and kidney). (Photos courtesy of X. Bai and T.V. Bowman.) 
mass (ICM) region from posterior lateral mesoderm (PLM) (Detrich et al. 1995) and the emergence of primitive myeloid cells $\left(p u .1^{+}\right)$from anterior lateral mesoderm (ALM) (Herbomel et al. 1999; Bennett et al. 2001). This initial wave of blood production is equivalent to blood formation on the extraembryonic yolk sac of other vertebrates. The primary function of primitive hematopoiesis is to provide red blood cells to deliver oxygen within the rapidly developing embryo. Although dispensable in zebra fish, this property allows primitive blood mutants to be studied in the fish because early blood defects in most other vertebrates are embryonic-lethal.

Soon after the formation of the ICM, erythromyeloid progenitor cells $\left(\right.$ lmo2-gatal $\left.^{+}\right)$appear in the posterior blood island (PBI) located in the tail region (Bertrand et al. 2007), and a wave of definitive HSC (runx $1^{+}, \mathrm{c}-m y b^{+}$, ikaros $^{+}$, $\mathrm{lmo}^{+}, \mathrm{SCl}^{+}$, and $\mathrm{CD} \mathrm{I}^{+}$) production ensues in the aortagonad-mesonephros (AGM) region along the ventral wall of the dorsal aorta (Liao et al. 1998; Thompson et al. 1998; Willett et al. 2001; Kalev-Zylinska et al. 2002; Bertrand et al. 2008; Kissa et al. 2008). These AGM cells subsequently colonize the caudal hematopoietic tissue (CHT), an expansion of the PBI, as well as the thymus and kidney (Murayama et al. 2006; Jin et al. 2007; Kissa et al. 2008).

These secondary hematopoietic tissues provide a niche for blood progenitors to expand and begin to differentiate. The CHT is similar to mouse placenta or fetal liver, and developing lymphoid and myeloid cells in this region can be identified by markers such as c-myb, scl, runx 1 , and ikaros (Murayama et al. 2006; Zhang and Rodaway 2007). Thymic immigrants differentiate into $\mathrm{ragl}^{+}$lymphoid cells (Murayama et al. 2006; Jin et al. 2007; Kissa et al. 2008). The kidney is the adult hematopoietic organ in zebra fish equivalent to mammalian bone marrow, and like the CHT, c-myb, scl, runxl, and ikaros are expressed in this region (Murayama et al. 2006; Jin et al. 2007). Within the kidney marrow, HSCs reside adjacent to renal tubule epithelial cells (Kobayashi et al. 2008).

\section{ORIGIN OF BLOOD CELLS: HEMANGIOBLASTS AND HEMOGENIC ENDOTHELIUM}

Currently, it is thought that blood and vascular cells derive from a common progenitor based on shared marker expression and physical proximity between the two cell types during development. The lack of blood and vascular markers in developing zebra fish cloche (clo) mutants provides evidence for the existence of hemangioblasts (Strainier et al. 1995; Thompson et al. 1998), further supported by recent fate-mapping experiments in the early embryo. Photoactivation of fluorescein dextran in single cells within the ventral mesoderm at shield stage (6 hours postfertilization [hpf]) labeled blood and vascular cells later at $30 \mathrm{hpf}$ (Vogeli et al. 2006).

Definitive HSCs are believed to arise from the hemogenic endothelium (Jaffredo et al. 1998; de Brujin et al. 2002) and are transplantable and capable of multilineage differentiation (Cumano et al. 1996; Medvinsky and Dzierzak 1996). In addition, other data suggest that mesenchymal cells ventral to the dorsal aorta have HSC poten- tial (North et al. 2002). By analogy, HSCs produced within the zebra fish AGM region are believed to be equivalent to those found in the same region in mice, supported by expression of homologous markers and lineagetracing data. Furthermore, hematopoietic mutants such as clo and spadetail (spt) that disrupt formation of the dorsal aorta show loss of HSC induction (Thompson et al. 1998).

\section{TRANSCRIPTIONAL REGULATORS OF HSC FORMATION}

Specification of hematopoietic cells involves both the action of master blood transcriptional regulators and signaling molecules from the surrounding tissues. The transcription factors important for hematopoiesis in zebra fish are listed in Table 1. Many of them have been implicated in blood development by the blood-specific roles these factors have in other vertebrates or by genetic analysis of mutants isolated from large-scale screens (Fig. 2). Together, they

Table 1. Hematopoietic transcription factors in zebra fish

\begin{tabular}{|c|c|c|c|}
\hline Gene & Family & $\begin{array}{l}\text { Loss of } \\
\text { function }\end{array}$ & Reference \\
\hline$s c l$ & $\begin{array}{l}\text { basic helix } \\
\text { loop helix }\end{array}$ & morphant & Dooley et al. (2005) \\
\hline clebpl & bZIP & morphant & Su et al. (2007) \\
\hline clebpa & bZIP & - & Lyons et al. (2001) \\
\hline clebpb & bZIP & - & Lyons et al. (2001) \\
\hline tifly & $\begin{array}{l}\text { B box, PHD, } \\
\text { Bromo }\end{array}$ & moonshine & Ransom et al. (2004) \\
\hline$c b f b$ & $\begin{array}{l}\text { core-binding } \\
\text { factor }\end{array}$ & - & Blake et al. (2000) \\
\hline ets 1 & ETS & - & Zhu et al. (2005) \\
\hline etsrp & ETS & $y 11$ & Pham et al. (2007) \\
\hline mef & ETS & - & Zhu et al. (2005) \\
\hline pu.1 & ETS & morphant & Rhodes et al. (2005) \\
\hline flila & ETS & - & Brown et al. (2000) \\
\hline$c d x 1 a$ & homeobox & morphant & $\begin{array}{l}\text { Davidson and Zan } \\
\text { (2006) }\end{array}$ \\
\hline$c d x 4$ & homeobox & kugelig & Davidson et al. (2003) \\
\hline hhex & homeobox & deletion b16 & Liao et al. (2000) \\
\hline$l d b 1$ & $\begin{array}{l}\text { LIM domain } \\
\text { binding }\end{array}$ & - & Toyama et al. (1998) \\
\hline $\operatorname{lmo} 2$ & LIM domain & morphant & Patterson et al. (2007) \\
\hline runx 1 & runt & morphant & $\begin{array}{l}\text { Kalev-Zylinska et al. } \\
(2002)\end{array}$ \\
\hline runx3 & runt & morphant & $\begin{array}{l}\text { Kalev-Zylinska et al. } \\
(2003)\end{array}$ \\
\hline stat 5 & STAT & morphant & $\begin{array}{l}\text { Paffett-Lugassy et al. } \\
\text { (2007) }\end{array}$ \\
\hline$t b \times 16$ & $\mathrm{~T}$ box & spadetail & Thompson et al. (1998) \\
\hline $\operatorname{trf} 3$ & TBP & morphant & Hart et al. (2007) \\
\hline $\mathrm{c}-m y b$ & zinc finger & $\begin{array}{c}\text { deletion } \\
\text { b316 }\end{array}$ & Thompson et al. (1998) \\
\hline draculin & zinc finger & - & Herbomel et al. (1999) \\
\hline fog 1 & zinc finger & - & Nishikawa et al. (2003) \\
\hline gatal & zinc finger & vlad tepes & Detrich et al. (1995) \\
\hline gata2 & zinc finger & morphant & Galloway et al. (2005) \\
\hline gfil.1 & zinc finger & morphant & Wei et al. (2008) \\
\hline ikaros & zinc finger & - & Willett et al. (2001) \\
\hline klfd & zinc finger & - & Oates et al. (2001) \\
\hline klf4 & zinc finger & morphant & Gardiner et al. (2007) \\
\hline klf12 & zinc finger & - & Oates et al. (2001) \\
\hline$n f e 2$ & zinc finger & - & Pratt et al. (2002) \\
\hline$Z B P-89$ & zinc finger & morphant & Li et al. (2006) \\
\hline
\end{tabular}

Adapted from Davidson and Zon (2004). 


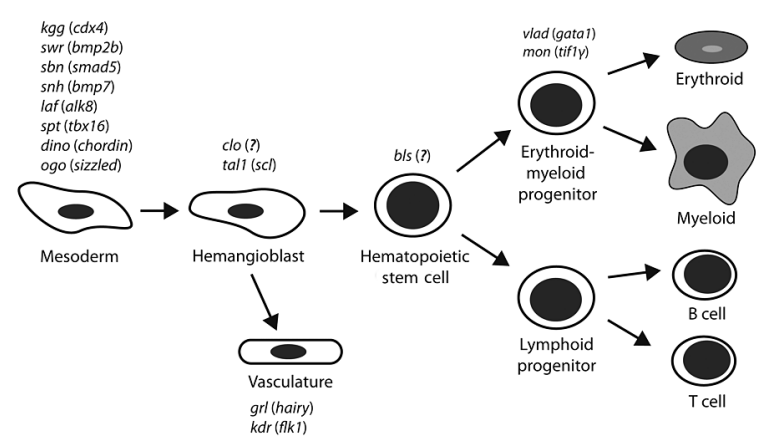

Figure 2. Mutants affecting blood development in zebra fish. Corresponding genes are in parenthesis.

form a transcriptional network that directs various aspects of the blood program from specification to differentiation.

$\mathrm{scl}$ and $\mathrm{lmo} 2$ are expressed in hematopoietic progenitors and endothelial cells, possibly acting together to specify the hemangioblast (Patterson et al. 2007). scl encodes a basic helix-loop-helix transcription factor, whereas $1 m o 2$ is a LIM-domain transcription factor. $s c l$ expression is initiated at $10 \mathrm{hpf}$ and is coexpressed with lmo2, gata2, and flkl in the ALM and PLM (Gering et al. 1998; Thompson et al. 1998). A subset of these $s c l^{+}$cells in the PLM becomes gatal $^{+}$, committing to the erythroid lineage, whereas the $\mathrm{SCl}^{+} / \mathrm{gatal}^{-}$population is believed to form endothelial cells (Gering et al. 1998). In the ALM, pu.1 expression is initiated with the differentiation of myeloid cells (Bennett et al. 2001). Overexpression of $\mathrm{scl}$ and $\mathrm{lmo} 2$ expands the formation of blood and vascular progenitors along the anteroposterior (AP) axis (Gering et al. 2003), although $s c l$ itself is capable of activating hematopoietic genes independently of $\operatorname{lmo} 2$ (Dooley et al. 2005). Once primitive erythroblasts from the ICM enter the circulation, additional markers appear that define the definitive wave.

Targeted disruption of runx 1 in mice has demonstrated its requirement for HSC induction in the AGM (Okuda et al. 1996; North et al. 2002). In zebra fish, runxl and c-myb are expressed in the AGM as well (Thompson et al. 1998; Burns et al. 2002; Gering and Patient 2005). runxl is a member of the runt family of transcriptional regulators involved in many developmental processes including blood and bone development in mammals. In zebra fish, runxl is first expressed in the bilateral stripes of the PLM that then migrate to the midline to form the ICM. It subsequently appears during the definitive wave in the ventral wall of the dorsal aorta (Burns et al. 2002). runxl overexpression causes HSC expansion in embryos, whereas morpholino knockdown causes defects in definitive hematopoiesis and vasculoangiogenesis (Burns et al. 2005). Furthermore, c-myb expression is reduced in runx 1 morphants (Kalev-Zylinska et al. 2002).

runx 3 was found to regulate primitive and definitive hematopoietic cells but not vascular cells. Depletion of runx 3 resulted in decreased runx 1 expression in the ventral wall of the dorsal aorta. Conversely, overexpression of runx 3 increased primitive $S \mathrm{Sl}^{+}$cell numbers and runx $\mathrm{I}^{+}$cells in the aorta, suggesting that runx 3 regulates hematopoietic pro- genitor numbers and cooperates with runxl to regulate HSC formation in the AGM (Kalev-Zylinska et al. 2003).

c-myb encodes a proto-oncogene that marks the initiation of HSCs in the ventral wall of the dorsal aorta. In zebra fish, it is expressed in primitive erythroid cells in the ICM region, but it is not required for the primitive wave (Thompson et al. 1998). Expression then shifts to the ventral wall of the dorsal aorta, presumably marking the definitive HSCs in the AGM region. Although these c-my $b^{+}$cells have not been transplanted, the lack of c-myb expression in clo and spt mutants provides further evidence for c-myb as a marker of definitive HSCs (Thompson et al. 1998).

The contribution of the $c d x$-hox pathway to specification of hematopoietic cell fate has been elucidated in zebra fish. $c d x$ genes belong to the caudal family of homeobox transcription factors implicated in the regulation of hox gene expression and in AP patterning. Both $c d x l a$ and $c d x 4$ establish the correct hox expression domains necessary for blood development in zebra fish (Davidson and Zon 2006). Loss of $c d x 4$ gene function in homozygous kugelig ( $\mathrm{kgg}$ ) mutants results in severe anemia with embryos having few $\mathrm{Scl}^{+}$and gatal $^{+}$cells, although the number of $f l k 1^{+}$angioblasts appears to be normal. All hox genes examined (hoxb4, hoxb5a, hoxb6b, hoxb7a, hoxb $8 a$, hoxb $8 b$, and hoxa $9 a$ ) displayed altered expression patterns in $\mathrm{kgg}$ mutants, but overexpression of hoxb $7 \mathrm{a}$ and hox9a could rescue erythropoiesis (Davidson et al. 2003). This pathway regulating blood specification was recently found to be conserved in mouse embryonic stem (ES) cells (Lengerke et al. 2008).

Additional transcription factors important for definitive hematopoiesis include flila, hhex, and tbxl6. flila is an ETS-domain transcription factor implicated in proliferation or differentiation of hematopoietic precursors. It is coexpressed in the hemangioblasts of the PLM with gata2, diverging later to mark only the endothelial cells (Brown et al. 2000). Given that its initial expression is normal in clo mutants, flila may be the earliest marker of hemangioblasts. hhex encodes a homeobox-containing protein whose expression begins about $12 \mathrm{hpf}$ in the ALM and PLM. Overexpression enhances blood and endothelial markers but is not essential for their development, which can be compensated by $\mathrm{scl}$ (Liao et al. 2000). tbx 16 encodes a T-box transcription factor that regulates mesodermal cell migration, which is defective in spt mutants. As described previously, abnormal somite patterning and accumulation of mesodermal cells perturb vessel formation, which subsequently leads to defective HSC formation as demonstrated by loss of hematopoietic markers gata2, gatal, and runx 1 in the PLM (Ho and Kane 1990; Thompson et al. 1998). Overexpression of $\mathrm{scl}$ rescues blood formation in $\mathrm{spt}$ mutants, indicating that $t b x 16$ is upstream of $s c l$ in directing HSC formation (Dooley et al. 2005).

The analogous expression of these different markers in zebra fish and other vertebrate models suggests that the molecular mechanisms are highly conserved. Once the hematopoietic precursors have been specified, additional blood transcription factors such as gata1, pu.1, and ikaros direct the lineage-specific differentiation of these progenitors into erythroid, myeloid, and lymphoid cell types, respectively. Some of the factors required for HSC forma- 
tion (runxl, scl, and lmo2) reappear later within the differentiation of individual blood lineages, and conversely, factors that have more lineage-restricted roles (pu.1) can also be found in HSCs (Orkin and Zon 2008). How the same transcription factors are used at various stages of hematopoietic development is not well understood, but the fact that many of these genes are mutated or translocated in human hematopoietic malignancies underscores the importance of these transcription factors in blood development throughout the life of an animal.

\section{PATHWAYS IN THE INDUCTION OF HSCS}

In addition to transcriptional regulators, signal transduction pathways are also important for modulating blood formation. Although distinct hematopoietic precursors are generated in different anatomical sites, common signaling events at each site are expected to lead to blood formation. How these different signaling pathways are coupled to control stem cell induction and development is a subject of ongoing research.

The family of Hedgehog (Hh) proteins are known to be involved in embryonic patterning and cell-fate specification. Based on murine mutants, there was no role for $\mathrm{Hh}$ signaling in hematopoiesis (Dyer et al. 2001; Byrd et al. 2002). In zebra fish, Hh was found to be required for definitive but not primitive hematopoiesis (Gering and Patient 2005). It is secreted by midline structures (floor plate, notochord, and hypochord) in the developing embryo. When Hh signaling is inhibited by chemicals or in genetic mutants, embryos showed normal numbers of $\beta$-globinE $1^{+}$ primitive erythrocytes but reduced $r u n x 1^{+}$definitive stem cells and $\mathrm{rag}^{+}$thymocytes, suggesting that $\mathrm{Hh}$ is required only for induction of definitive HSCs. Impaired medial migration of $f l k 1^{+}$angioblasts was also observed, indicating the possibility that improper patterning of the aorta is the cause of HSC loss. These effects were similar to those seen with vascular endothelial growth factor (VEGF) and Notch inhibition (Gering and Patient 2005).

Notch signaling has been previously shown to be required for induction of HSCs during embryogenesis in mice (Okuda et al. 1996). The Notch pathway is highly conserved throughout evolution, regulating cell-fate decisions in a wide range of biological processes. Using zebra fish mind bomb mutants that lack an E3 ubiquitin ligase essential for Notch signaling, runxl was identified as a downstream effector (Burns et al. 2005). Overexpression of notchla intracellular domain (NICD) expanded the population of c- $m y b^{+}$and $r u n x l^{+}$cells in the AGM region, and this increase was not due to proliferation or conversion of vein-to-artery identity. This phenotype was recapitulated in runxl overexpressing embryos (Burns et al. 2005). Given that it rescues the mind bomb phenotype, runx 1 may be acting in parallel or downstream from Notch signaling. In addition, runx 1 morphants show reduced c$\mathrm{myb}^{+}$and ikaros $^{+}$cells at $50 \mathrm{hpf}$ and loss of $\mathrm{ragl}^{+}$thymocytes at 6 days (Gering and Patient 2005).

A new pathway modulating HSC formation by prostaglandins was recently identified in the zebra fish. Prostaglandins are part of the eicosanoid signal transduction pathway, with prostaglandin E2 (PGE2) being the main effector prostanoid produced in the zebra fish. They are regulated by cyclooxygenases Cox 1 and Cox2 (Grosser et al. 2002). When treated with PGE2, zebra fish embryos showed increased runx $1^{+}$and $c m y b^{+}$cells in the AGM region by in situ hybridization, confocal microscopy, and quantitative polymerase chain reaction (PCR). Chemical or morpholino inhibition of the pathway reduced HSC formation. These results were verified in both colony-forming and -limiting dilution competitive transplantation assays in the mouse, demonstrating a functional conservation of prostaglandin signaling not only in inducing HSCs, but also in adult maintenance (North et al. 2007). 16,16-Dimethyl-PGE2 (dmPGE2), a stable derivative of PGE2, will be tested in a human phase I clinical trial to determine whether it can improve the efficiency of cord blood transplantations (Lord et al. 2007).

\section{MIGRATORY ROUTES OF HSCS TO SECONDARY HEMATOPOIETIC SITES}

The ontogeny of HSCs in the AGM region is followed by subsequent colonization of secondary hematopoietic sites, presumably as different niches become available to support HSC growth within the constantly evolving microenvironment of the developing embryo. Lineage tracing in the mouse has been complicated by the inability to stage embryos precisely in utero and to determine the kinetics of conditional recombination activity, making it difficult to identify clearly the anatomic origins of adult HSCs. One advantage of performing in vivo fate mapping in zebra fish is the optical transparency and external development of its embryos.

Live imaging of cells labeled with green fluorescent protein (GFP) driven by HSC-specific promoters, such as $C D 41$ and c- $m y b$, and caged fluorescein-dextran cell-tracing experiments have shown that HSCs from the AGM region migrate to colonize the $\mathrm{CHT}$, thymus, and pronephros (Murayama et al. 2006; Jin et al. 2007; Zhang and Rodaway 2007; Bertrand et al. 2008; Kissa et al. 2008). CD41 marks HSCs in the mouse (Mitjavila-Garcia et al. 2002; Ferkowicz et al. 2003; Mikkola et al. 2003). In zebra fish, both $C D 41-\mathrm{GFP}^{+}$and c- $m y b-\mathrm{GFP}^{+}$cells were observed in the AGM region, consistent with runxl expression at the same site (North et al. 2007; Kissa et al. 2008). Knockdown of runxl suppressed the appearance of CD41-GFP ${ }^{+}$cells in this region, the CHT, and thymus (Kissa et al. 2008). Transplantation of $C D 41-\mathrm{GFP}^{+} \mathrm{AGM}$ cells into sibling embryonic recipients demonstrated colonization of the thymus and CHT (Bertrand et al. 2008), although assays have yet to be developed in the zebra fish that can support long-term reconstitution of embryonic donor cells.

Unlike chick and mouse, where AGM HSCs presumably bud off into circulation from intra-aortic clusters, AGM cells in zebra fish enter the circulation through the cardinal vein (CV) to seed the CHT (Kissa et al. 2008). Migration to the CHT requires circulation because CD41$\mathrm{GFP}^{+}$and c-my $b^{+}$cells were not found in the CHT of silent heart (sih) morphants (Murayama et al. 2006), which lack blood flow due to disruption of cardiac tropomyosin. Seeding of the thymus occurs by both circulation and 
migration through the mesenchyme from either the AGM or the CHT. These cells then proliferate and generate rag $1^{+}$T-lymphocyte precursors (Murayama et al. 2006; Kissa et al. 2008).

Recently, a novel route was found for HSCs to seed the kidney. Using time-lapse imaging of CD41-GFP and c$m y b$-GFP transgenic animals, hematopoietic cells were observed crawling along the pronephric tubules from the AGM toward the anterior glomeruli (Bertrand et al. 2008). The migration appears to be circulation-independent given that it remains intact in sih morphants. These migrating cells were found to express runx 1 and the panhematopoietic marker $C D 45$ as well, suggesting that they are stem cells (Bertrand et al. 2008).

\section{ADVANCES IN ZEBRA FISH FOR THE STUDY OF HSCS}

The power of the zebra fish model lies in the ability to perform large-scale genetic screens. Both forward genetic screens, using $N$-ethyl- $N$-nitrosourea (ENU) (Haffter et al. 1996; Weinstein et al. 1996) or insertional mutagenesis (Amsterdam et al. 1999), and reverse genetic screens, using targeted induced local lesions in genomes (TILLING) (Wienholds et al. 2002) and morpholinos, have been described. Zebra fish also provide a unique platform for conducting in vivo whole-animal chemical screening to identify novel compounds of therapeutic value. Although a number of hematopoietic mutants have been isolated from previous screens, a small number affect HSCs (Fig. 2); continued screening thus has the potential to generate new mutations that affect other pathways or regulators of HSC development. More precise genetic manipulations in zebra fish can be accomplished with transgenic fish, for example, using the heat shock Cre/lox system to induce tissue-specific gene expression (Feng et al. 2007). Recently, zinc finger nucleases have been used successfully for inducing targeted mutations in the germ line (Meng et al. 2008). The combination of these molecular methods makes it feasible to perform very precise genetic manipulations in zebra fish.

Assays that test stem cell function have also been developed in zebra fish. The major blood lineages (erythroid, lymphoid, myeloid, and precursors) can be segregated by flow cytometry using only the forward scatter and side scatter profiles (Traver et al. 2003); thus, multilineage reconstitution can be measured in irradiation-recovery or transplantation assays (Fig. 3, top left and bottom) (Traver et al. 2004). This method was used to determine the contribution of Notch and prostaglandin signaling to adult hematopoiesis, because these were both identified initially as regulators of HSC induction during embryogenesis (Burns et al. 2005; North et al. 2007). A brief dose of Notch activation or treatment with PGE2 enhanced marrow recovery postirradiation by expanding early multilineage precursors. runx $1, \mathrm{lmo} 2, \mathrm{scl}$, and even flil expression were significantly up-regulated in these cells (Burns et al. 2005; North et al. 2007). The effects of PGE2 were verified by limiting dilution transplantation assays of HSCs in the mouse (North et al. 2007). Although the mechanism by which these pathways enhance recovery remains unknown, they are ideal candidates for clinical use
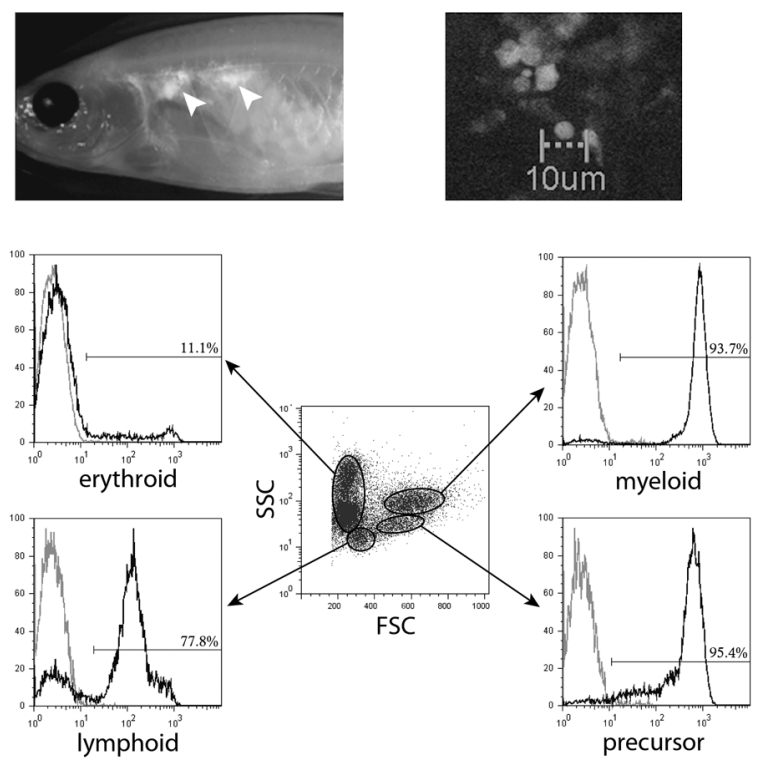

Figure 3. Multilineage reconstitution posttransplantation of transparent casper fish. (Top left) $\beta$-actin:GFP cells transplanted into irradiated casper fish show engraftment at 4 weeks posttransplantation. (White arrowheads) $\mathrm{GFP}^{+}$cells observed in the kidney by fluorescent microscopy. (Top right) In vivo visualization of recipient kidney marrow by confocal laser scanning shows single $\mathrm{GFP}^{+}$cells. Bar, $10 \mu \mathrm{m}$. (Bottom) Whole kidney marrow isolated from transplanted fish can be sorted into erythroid, lymphoid, myeloid, and precursor cells by flow cytometry based on forward scatter (FSC) and side scatter (SSC). Histograms of $\mathrm{GFP}^{+}$cells show reconstitution in the lymphoid, myeloid, and precuror populations. (Top right, Reprinted, with permission, from White et al. 2008 [C Cell Press]; bottom, images courtesy of J. de Jong.)

because any chemical that can enhance their signaling may have the potential to improve patient recovery posttransplantation by stimulating hematopoietic stem and progenitor cells.

Finally, visualization of HSCs in adult fish is now facilitated due to the recent development of a transparent zebra fish called casper (White et al. 2008). casper fish are doubly mutant for the nacre allele (encoding the mitfa gene) and the roy allele (encoding an unknown pigment gene), which blocks the development melanocytes and iridophores, respectively. As a result, the lack of pigmentation allows internal organs such as the heart, intestinal tube, liver, and gallbladder to be observed in vivo with the naked eye (White et al. 2008). HSC homeostasis could be studied in the casper fish within the context of the endogenous marrow niche, which has been a traditionally difficult process to observe. The ability to use these fish for examining the kinetics of stem cell homing and engraftment in the transplantation setting with resolution down to the single-cell level is currently unparalleled in other model systems (Fig. 3, top left and right).

\section{CONCLUSIONS}

Studies of HSCs in zebra fish have complemented investigations in other model organisms and have advanced our 
understanding of hematopoiesis. Much of what has been learned about the signaling pathways and transcription factors involved in the development of HSCs in zebra fish and other vertebrates is highly conserved. Given that zebra fish are amenable to large-scale screens, future genetic screens will continue to uncover new mutants with interesting hematopoietic phenotypes, and whole-animal chemical screening will identify new compounds of clinical value. In vivo screens are feasible using reporter lines and mutant and transgenic strains. As zebra fish methods advance, new opportunities for revealing more details of the molecular mechanisms of stem cell regulation will arise. Finally, the knowledge gained about HSCs will likely be applicable to stem cell biology in general.

\section{ACKNOWLEDGMENTS}

We thank X. Bai, J. de Jong, and R.M. White for a critical reading of the manuscript.

\section{REFERENCES}

Amsterdam, A., Burgess, S., Golling, G., Chen, W., Sun, Z., Townsend, K., Farrington, S., Haldi, M., and Hopkins, N. 1999. A large-scale insertional mutagenesis screen in zebrafish. Genes Dev. 13: 2713-2724.

Bennett, C.M., Kanki, J.P., Rhodes, J., Liu, T.X., Paw, B.H., Kieran, M.W., Langenau, D.M., Delahaye-Brown, A., Zon, L.I., Fleming, M.D., and Look, A.T. 2001. Myelopoiesis in the zebrafish, Danio rerio. Blood 98: 643-651.

Bertrand, J.Y., Kim, A.D., Ten, S., and Traver, D. 2008. CD41 ${ }^{+}$ $\mathrm{cmyb}^{+}$precursors colonize the zebrafish pronephros by a novel migration route to initiate adult hematopoiesis. Development 135: $1853-1862$.

Bertrand, J.Y., Kim, A.D., Violette, E.P., Stachura, D.L., Cisson, J.L., and Traver, D. 2007. Definitive hematopoiesis initiates through a committed erythromyeloid progenitor in the zebrafish embryo. Development 134: 4147-4156.

Blake, T., Adya, N., Kim, C.H., Oates, A.C., Zon, L., Chitnis, A., Weinstein, B.M., and Liu, P.P. 2000. Zebrafish homolog of the leukemia gene $C B F B$ : Its expression during embryogenesis and its relationship to $\mathrm{scl}$ and gata-1 in hematopoiesis. Blood 96: 4178-4184.

Brown, L.A., Rodaway, A.R., Schilling, T.F., Jowett, T., Ingham, P.W., Patient, R.K., and Sharrocks, A.D. 2000. Insights into early vasculogenesis revealed by expression of the ETSdomain transcription factor Fli-1 in wild-type and mutant zebrafish embryos. Mech. Dev. 90: 237-252.

Burns, C.E., DeBlasio, T., Zhou, Y., Zon, L.I., and Nimer, S.D. 2002. Isolation and characterization of runxa and runxb, zebrafish members of the runt family of transcriptional regulators. Exp. Hematol. 30: 1381-1389.

Burns, C.E., Traver, D., Mayhall, E., Shepard, J.L., and Zon, L.I. 2005. Hematopoietic stem cell fate is established by the Notch-Runx pathway. Genes Dev. 19: 2331-2342.

Byrd, N., Becker, S., Maye, P., Narasimhaiah, R., St-Jacques, B., Zhang, X., McMahon, J., McMahon, A., and Grabel, L. 2002. Hedgehog is required for murine yolk sac angiogenesis. Development 129: 361-372.

Carradice, D. and Lieschke, G.J. 2008. Zebrafish in hematology: Sushi or science? Blood 111: 3331-3342.

Cumano, A., Dieterlen-Lièvre, F., and Godin, I. 1996. Lymphoid potential, probed before circulation in mouse, is restricted to caudal intraembryonic splanchnopleura. Cell 86: 907-916.

Davidson, A.J. and Zon, L.I. 2004. The "definitive" (and "primitive") guide to zebrafish hematopoiesis. Oncogene 23: 7233 7246.

Davidson, A.J. and Zon, L.I. 2006. The caudal-related homeobox genes $c d x l a$ and $c d x 4$ act redundantly to regulate hox gene expression and the formation of putative hematopoietic stem cells during zebrafish embryogenesis. Dev. Biol. 292: 506518.

Davidson, A.J., Ernst, P., Wang, Y., Dekens, M.P.S., Kingsley, P.D., Palis, J., Korsmeyer, S.J., Daley, G.Q., and Zon, L.I. 2003. $c d x 4$ mutants fail to specify blood progenitors and can be rescued by multiple hox genes. Nature 425: 300-306.

de Bruijn, M.F., Ma, X., Robin, C., Ottersbach, K., Samchez, M.J., and Dzierzak, E. 2002. HSCs localize to the endothelial layer in the midgestation mouse aorta. Immunity 16: 673-683.

Detrich III, H.W., Kieran, M.W., Chan, F.Y., Barone, L.M., Yee, K., Rundstadler, J.A., Pratt, S., Ransom, D., and Zon, L.I. 1995. Intraembryonic hematopoietic cell migration during vertebrate development. Proc. Natl. Acad. Sci. 92: 1071310717.

Dooley, K.A., Davidson, A.J., and Zon, L.I. 2005. Zebrafish scl functions independently in hematopoietic and endothelial development. Dev. Biol. 277: 522-536.

Dyer, M.A., Farrington, S.M., Mohn, D., Munday, J.R., and Baron, M.H. 2001. Indian hedgehog activates hematopoiesis and vasculogenesis and can respecify prospective neuroectodermal cell fate in the mouse embryo. Development 128: 1717-1730.

Feng, H., Langenau, D.M., Madge, J.A., Quinkertz, A., Gutierrez, A., Neuberg, D.S., Kanki, J.P., and Look, T.A. 2007. Heat-shock induction of T-cell lymphoma/leukaemia in conditional Cre/lox-regulated transgenic zebrafish. Br. J. Haematol. 138: $169-175$.

Ferkowicz, M.J., Starr, M., Xie, X., Li, W., Johnson, S.A., Shelley, W.C., Morrison, P.R., and Yoder, M.C. 2003. CD41 expression defines the onset of primitive and definitive hematopoiesis in the murine embryo. Development 130: 4393-4403.

Galloway, J.L., Wingert, R.A., Thisse, C., Thisse, B., and Zon, L.I. 2005. Loss of gata1 but not gata2 converts erythropoiesis to myelopoiesis in zebrafish embryos. Dev. Cell 8: 109-116.

Gardiner, M.R., Gongora, M.M., Grimmond, S.M., and Perkins, A.C. 2007. A global role for zebrafish klf4 in embryonic erythropoiesis. Mech. Dev. 124: 762-774.

Gering, M. and Patient, R. 2005. Hedgehog signaling is required for adult blood stem cell formation in zebrafish embryos. Dev. Cell 8: $389-400$.

Gering, M., Yamada, Y., Rabbitts, T.S., and Patient, R.K. 2003. $\mathrm{Lmo} 2$ and $\mathrm{Scl} / \mathrm{Tal} 1$ convert non-axial mesoderm into haemangioblasts which differentiate into endothelial cells in the absence of Gata1. Development 130: 6187-6199.

Gering, M., Rodaway, A.R.F., Gottgens, B., Patient, R.K., and Green, A.R. 1998. The SCL gene specifies haemangioblast development from early mesoderm. EMBO J. 17: 4029-4045.

Grosser, T., Yusuff, S., Cheskis, E., Pack, M.A., and FitzGerald, G.A. 2002. Developmental expression of functional cyclooxygenases in zebrafish. Proc. Natl. Acad. Sci. 99: 8418-8423.

Haffter, P., Granato, M., Brand, M., Mullins, M.C., Hammerschmidt, M., Kane, D.A., Odenthal, J., van Eeden, F.J., Jiang, Y.J., Heisenberg, C.P., et al. 1996. The identification of genes with unique and essential functions in the development of the zebrafish, Danio rerio. Development 123: 1-36.

Hart, D.O., Raha, T., Lawson, N.D., and Green, M.R. 2007. Initiation of zebrafish haematopoiesis by the TATA-boxbinding protein-related factor Trf3. Nature 450: 1082-1085.

Herbomel, P., Thisse, B., and Thisse, C. 1999. Ontogeny and behavior of early macrophages in the zebrafish embryo. Development 126: 3735-3745.

Ho, R.K. and Kane, D.A. 1990. Cell-autonomous action of zebrafish spt-1 mutation in specific mesodermal precursors. Nature 348: 728-730.

Jaffredo, T., Gautier, R., Eichmann, A., and Dieterlen-Lièvre, F. 1998. Intraaortic hemopoietic cells are derived from endothelial cells during ontogeny. Development 125: 4575-4583.

Jin, H., Xu, J., and Wen, Z. 2007. Migratory path of definitive hematopoietic stem/progenitor cells during zebrafish development. Blood 109: 5208-5214.

Kalev-Zylinska, M.L., Horsfield, J.A., Flores, M.V.C., Postlethwait, J.H., Vitas, M.R., Baas, A.M., Crosier, P.S., and Crosier, 
K.E. 2002. Runx 1 is required for zebrafish blood and vessel development and expression of a human RUNX1-CBF2T1 transgene advances a model for studies of leukemogenesis. Development 129: 2015-2030.

Kalev-Zylinska, M.L., Horsfield, J.A., Flores, M.V.C., Postlethwait, J.H., Chau, J.Y.M., Cattin, P.M., Vitas, M.R., Crosier, P.S., and Crosier, K.E. 2003. Runx3 is required for hematopoietic development in zebrafish. Dev. Dyn. 228: 323-336.

Kissa, K., Murayama, E., Zapata, A., Cortes, A., Perret, E., Machu, C., and Herbomel, P. 2008. Live imaging of emerging hermatopoietic stem cells and early thymus colonization. Blood 111: $1147-1156$

Kobayashi, I., Saito, K, Moritomo, T., Araki, K., Takizawa, F., and Nakanishi, T. 2008. Characterization and localization of side population (SP) cells in zebrafish kidney hematopoietic tissue. Blood 111: 1131-1137.

Lengerke, C., Schmitt, S., Bowman, T.V., Jang, I.H., MaoucheChretien, L., McKinney-Freeman, S., Davidson, A.J., Hammerschmidt, M., Rentzsch, F., Green, J.B.A., Zon, L.I., and Daley, G.Q. 2008. BMP and Wnt specify hematopoietic fate by activation of the Cdx-Hox pathway. Cell Stem Cell 2: 72-82.

Li, X., Xiong, J.W., Shelley, C.S., Park, H., and Arnaout, M.A. 2006. The transcription factor ZBP-89 controls generation of the hematopoietic lineage in zebrafish and mouse embryonic stem cells. Development 133: 3641-3650.

Liao, E.C., Paw, B.H., Oates, A.C., Pratt, S.J., Postlethwait, J.H., and Zon, L.I. 1998. SCL/Tal-1 transcription factor acts downstream of cloche to specifiy hematopoietic and vascular progenitors in zebrafish. Genes Dev. 12: 621-626.

Liao, W., Ho, C.Y., Yan, Y.L., Postlethwait, J., and Stainier, D.Y. 2000. Hhex and scl function in parallel to regulate early endothelial and blood differentiation in zebrafish. Development 127: 4303-4313.

Lord, A.M., North, T.E., and Zon, L.I. 2007. Prostaglandin E2: Making more of your marrow. Cell Cycle 6: 3054-3057.

Lyons, S.E., Shue, B.C., Lei, L., Oates, A.C., Zon, L.I., and Liu, P.P. 2001. Molecular cloning, genetic mapping, and expression analysis of four zebrafish c/ebp genes. Gene 281: 43-51.

Medvinsky, A. and Dzierzak, E. 1996. Definitive hematopoiesis is autonomously initiated by the AGM region. Cell 86: $897-$ 906.

Meng, X., Noyes, M.B., Zhu, L.J., Lawson, N.D., and Wolfe, S.A. 2008. Targeted gene inactivation in zebrafish using engineered zinc-finger nucleases. Nat. Biotechnol. 26: 695-701.

Mikkola, H.K., Fujiwara, Y., Schlaeger, T.M., Traver, D., and Orkin, S.H. 2003. Expression of CD41 marks the initiation of definitive hematopoiesis in the mouse embryo. Blood 101: 508-516.

Mitjavila-Garcia, M.T., Cailleret, M., Godin, I., Nogueira, M.M., Cohen-Solal, K., Schiavon, V., Lecluse, Y., Le Pesteur, F., Lagrue, A.H., and Vainchenker, W. 2002. Expression of CD41 on hematopoietic progenitors derived from embryonic hematopoietic cells. Development 129: 2003-2013.

Murayama, E., Kissa, K., Zapata, A., Mordelet, E., Briolat, V., Lin, H.F., Handin, R.I., and Herbomel, P. 2006. Tracing hematopoietic precursor migration to successive hematopoietic organs during zebrafish development. Immunity 25: 963 975.

Nishikawa, K., Kobayashi, M., Masumi, A., Lyons, S.E., Weinstein, B.M., Liu, P.P., and Yamamoto, M. 2003. Self-association of Gata1 enhances transcriptional activity in vivo in zebra fish embryos. Mol. Cell Biol. 23: 8295-8305.

North, T.E., de Bruijn, M.F., Stacey, T., Talebian, L., Lind, E., Robin, C., Binder, M., Dzierzack, E., and Speck, N.A. 2002. Runx1 expression marks long-term repopulating hematopoietic stem cells in the midgestation mouse embryo. Immunity 16: 661-672.

North, T.E., Goessling, W., Walkley, C.R., Lengerke, C., Kopani, K.R., Lord, A.M., Weber, G.J., Bowman, T.V., Jang, I.H., Grosser, T., et al. 2007. Prostaglandin E2 regulates vertebrate haematopoietic stem cell homeostasis. Nature 447: 1007-1011.

Oates, A.C., Pratt, S.J., Vail, B., Yan, Y.I., Ho, R.K., Johnson, S.L., Postlethwait, J.H., and Zon, L.I. 2001. The zebrafish klf gene family. Blood 98:1792-1801.
Okuda, T., van Deursen, J., Hiebert, S.W., Grosveld, G., and Downing, J.R. 1996. AML1, the target of multiple chromosomal translocations in human leukemia, is essential for normal fetal liver hematopoiesis. Cell 84: 321-330.

Orkin, S.H. and Zon, L.I. 2008. Hematopoiesis: An evolving paradigm for stem cell biology. Cell 132: 631-644.

Patterson, L.J., Gering, M., Eckfeldt, C.E., Green, A.R., Verfaillie, C.M., Ekker, S.C., and Patient, R. 2007. The transcription factors $\mathrm{Scl}$ and $\mathrm{Lmo} 2$ act together during development of the hemangioblast in zebrafish. Blood 109: 2389-2398

Paffett-Lugassy, N., Hsia, N., Fraenkel, P.G., Paw, B., Leshinsky, I., Barut, B., Bahary, N., Caro, J., Handin, R., and Zon, L.I. 2007. Functional conservation of erythropoietin signaling in zebrafish. Blood 110: 2718-2726.

Pham, V.N., Lawson, N.D., Mugford, J.W., Dye, L., Castranova, D., Lo, B., and Weinstein, B.M. 2007. Combinatorial function of ETS transcription factors in the developing vasculature. Dev. Biol. 303: 772-783.

Pratt, S.J., Drejer, A., Foott, H., Barut, B., Brownlie, A., Postlethwait, J., Kato, Y., Yamamoto, M., and Zon, L.I. 2002. Isolation and characterization of zebrafish NFE2. Physiol. Genomics 11: 91-98.

Ransom, D.G., Bahary, N., Niss, K., Traver, D., Burns, C. Trede, N.S., Paffett-Lugassy, N., Saganic, W.J., Lim, C.A., Hersey, C., et al. 2004. The zebrafish moonshine gene encodes transcriptional intermediary factor $1 \gamma$, an essential regulator of hematopoiesis. PloS Biol. 2: E237.

Ransom, D.G., Haffter, P., Odenthal, J., Brownlie, A., Vogelsang, E., Kelsh, R.N., Brand, M., van Eeden, F.J., Furutani-Seiki, M., Granato, M., et al. 1996. Characterization of zebrafish mutants with defects in embryonic hematopoiesis. Development 123: 311-319.

Rhodes, J., Hagen, A., Hsu, K., Deng, M., Liu, T.X., Look, A.T., and Kanki, J.P. 2005. Interplay of pu.1 and gatal determines myelo-erythroid progenitor cell fate in zebrafish. Dev. Cell 8: 97-108.

Stainier, D.Y.R., Weinstein, B.M., Detrich III, H.W., Zon, L.I., and Fishman, M.C. 1995. cloche, an early acting zebrafish gene, is required by both the endothelial and hematopoietic lineages. Development 121: 3141-3150.

$\mathrm{Su}$, F., Juarez, M.A., Cooke, C.L., Lapointe, L., Shavit, J.A., Yamaoka, J.S., and Lyons, S.E. 2007. Differential regulation of primitive myelopoiesis in the zebrafish by Spi-1/Pu.1 and C/ebp1. Zebrafish 4: 187-199.

Thompson, M.A., Ransom, D.G., Pratt, S.J., MacLennan, H., Kieran, M.W., Detrich III, H.W., Vail, B., Huber, T.L., Paw, B., Brownlie, A.J., et al. 1998. The cloche and spadetail genes differentially affect hematopoiesis and vasculogenesis. Dev. Biol. 197: 248-269.

Toyama, R., Kobayashi, M., Tomita, T., and Dawid, I.B. 1998. Expression of LIM-domain binding protein (ldb) genes during zebrafish embryogenesis. Mech. Dev. 71: 197-200.

Traver, D., Paw, B.H., Poss, K.D., Penberthy, W.T., Lin, S., and Zon, L.I. 2003. Transplantation and in vivo imaging of multilineage engraftment in zebrafish bloodless mutants. Nat. Immunol. 4: 1238-1246.

Traver, D., Winzeler, A., Stern, H.M., Mayhall, E.A., Langenau, D.M., Kutok, J.L., Look, A.T., and Zon, L.I. 2004. Effects of lethal irradiation in zebrafish and rescue by hematopoietic cell transplantation. Blood 104: 1298-1305.

Vogeli, K.M., Jin, S.W., Martin, G.R., and Stainier, D.Y.R. 2006. A common progenitor for hematopoietic and endothelial lineages in the zebrafish gastrula. Nature 443: 337-339.

Wei, W., Wen, L., Huang, P., Zhang, Z., Chen, Y., Xiao, A., Huang, H., Zhu, Z., Zhang, B., and Lin, S. 2008. Gfil.1 regulates hematopoietic lineage differentiation zebrafish embryogenesis. Cell Res. 18: 677-685.

Weinstein, B.M., Schier, A.F., Abdelilah, S., Malicki, J., SolnicaKrezel, L., Stemple, D.L., Stainier, D.Y., Zwartkruis, F., Driever, W., and Fishman, M.C. 1996. Hematopoietic mutations in the zebrafish. Development 123: 303-309.

White, R.M., Sessa, A., Burke, C., Bowman, T., LeBlanc, J., Ceol, C., Bourque, C., Dovey, M., Goessling, W., Burns, C.E., 
and Zon, L.I. 2008. Transparent adult zebrafish as a tool for in vivo transplantation analysis. Cell Stem Cell 2: 183-189.

Wienholds, E., Schulte-Merker, S., Walderich, B., and Plasterk, R.H.A. 2002. Targeted-selected inactivation of the zebrafish ragl gene. Science 297: 99-102.

Willett, C.E., Kawasaki, H., Amemiya, C.T., Lin, S., and Steiner, L.A. 2001. Ikaros expression as a marker for lymphoid progenitors during zebrafish development. Dev. Dyn. 222: 694-698.
Zhang, X.Y. and Rodaway, A.R.F. 2007. SCL-GFP transgenic zebrafish: In vivo imaging of blood and endothelial development and identification of the initial site of definitive hematopoiesis. Dev. Biol. 307: 179-194.

Zhu, H., Traver, D., Davidson, A.J., Dibiase, A., Thisse, C., Thisse, B., Nimer, S., and Zon, L.I. 2005. Regulation of the Imo 2 promoter during hematopoietic and vascular development in zebrafish. Dev. Biol. 281: 256-269. 


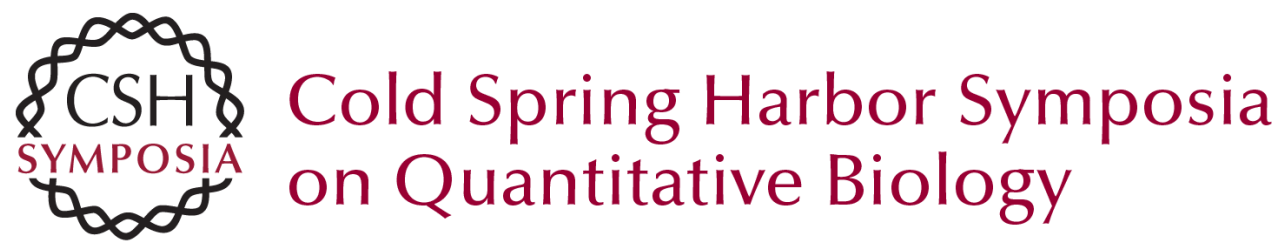

\section{Regulation of Stem Cells in the Zebra Fish Hematopoietic System}

H.-T. Huang and L.I. Zon

Cold Spring Harb Symp Quant Biol 2008 73: 111-118 originally published online November 6, 2008 Access the most recent version at doi:10.1101/sqb.2008.73.029

References This article cites 74 articles, 32 of which can be accessed free at: http://symposium.cshlp.org/content/73/111.full.html\#ref-list-1

License

Email Alerting Receive free email alerts when new articles cite this article - sign up in the box at the Service top right corner of the article or click here.

To subscribe to Cold Spring Harbor Symposia on Quantitative Biology go to:

http://symposium.cshlp.org/subscriptions 